\title{
Recrystallization in Multilayer Al99.99/AlMg3 Laminates Prepared by Accumulative Roll-Bonding
}

\author{
M. Cieslar*, M. Poková, M. Zimina, J. Veselý and J. Bajer \\ Charles University in Prague, Faculty of Mathematics and Physics, \\ Ke Karlovu 5, CZ-121 16 Prague 2, Czech Republic
}

\begin{abstract}
Composite multilayer sheets from $\mathrm{Al} / \mathrm{AlMg} 3$ with 32 alternating layers of $\mathrm{Al}$ and $\mathrm{AlMg} 3$ were prepared by accumulative roll-bonding and their thermal stability was studied. Recrystallized $2 \mathrm{~mm}$ thick sheets of a commercial twin-roll cast AlMg3 alloy and high purity A199.99 served as input materials. Electrical resistivity measurements were used for the integral monitoring of solute atoms distribution during annealing. Light optical microscopy was employed for the direct grain-size determination and recrystallization description. Post-mortem electron microscopy observations were performed on as-prepared and annealed specimens and they were combined with in situ heating electron microscopy in order to explain the observed annealing effects. A broadening of Al layers during annealing was observed and related to diffusion of magnesium.
\end{abstract}

DOI: 10.12693 /APhysPolA.128.487

PACS: 81.40.Ef, 81.40.Lm, 61.72.Ff, 81.40.-z

\section{Introduction}

New technologies of components assembling in car and aircraft industries and requests on improved mechanical and corrosion properties of metallic materials activate the utilization of highly innovative and unconventional manufacturing processes. In addition, a growing need in the decrease of fabrication costs and the limitation of the waste material in metal-forming processes result in the combination of non-traditional materials with modern casting methods and non-standard shaping. Twinroll cast (TRC) aluminum alloys represent a new class of materials that must undergo additional post processing in order to fully take advantage of their potential. Grain size is one of the most important parameters which control mechanical behavior of non age-hardenable aluminum alloys including TRC materials. Accumulative roll-bonding (ARB) [1] is a technique producing ultrafine grained (UFG) structures without geometrical change of TRC sheets using standard rolling equipment. Because two metal sheets are bonded during this process a proper selection of the material including a combination of two different alloys may help to achieve unique properties.

Recently several ARB experiments have been performed on a TRC AlMg3 alloy showing intensive strength increase after ARB accompanied, however, by a significant edge cracking [2]. Therefore low ductility of this ARB material represents an important weakness in many potential applications.

Experiments of Ma [3] have shown that a good compromise between good yield stress and ductility of UFG materials could be reached with bimodal grain size distribution. Thus cladding of the AlMg3 alloy with a high-purity

${ }^{*}$ corresponding author; e-mail: cieslar@met.mff.cuni.cz
TRC aluminum was used and considerable ductility improvement and cracking limitation was reached.

Finally, multilayered composites containing up to 64 alternating layers of $\mathrm{Al}$ and $\mathrm{AlMg} 3$ were prepared [4]. Ductility is ensured in this type of the material by partially recrystallized coarser grains in Al layers while fine-grained and heavily deformed microstructure of AlMg3 layers enhances the strength of the composite. Due to a different amount of stored energy and the presence of solutes and particles the softening processes occur in a different manner in both types of the stacked material during subsequent annealing. Because the final mechanical properties are given by the microstructure of the composite including the structure of the interface between the two bounded alloys, series of annealing experiments on $\mathrm{AlMg} 3 / \mathrm{Al}$ laminates after five $\mathrm{ARB}$ cycles were performed.

\section{Experimental details}

Recrystallized $2 \mathrm{~mm}$ thick TRC sheets of high purity Al99.99 and AlMg3 alloy (chemical composition (wt.\%): $2.6 \mathrm{Mg}, 0.2 \mathrm{Mn}, 0.2 \mathrm{Fe}$, and $0.05 \mathrm{Si}$ ) were used as input materials. Five cycles of ARB processing described in detail elsewhere [2] were performed at ambient temperature. Specimens were step-by-step isochronally annealed in an annealing regime $20^{\circ} \mathrm{C} / 20 \mathrm{~min}$ and quenched into water of room temperature (RT). Relative resistance changes in liquid nitrogen were measured after each annealing step. Grain structures were observed by light optical microscopy (LOM) under polarized light in the long transverse plain on specimens anodized by a Barker reagent. Transmission electron microscopy (TEM) foils were prepared by electrolytic twin-jet polishing in a solution of 30 vol. $\% \mathrm{HNO}_{3}$ in methanol $\left(-20^{\circ} \mathrm{C}, 15 \mathrm{~V}\right)$ and observed in JEOL JEM 2000FX electron microscope equipped with a single-tilt heating stage. 


\section{Results and discussion}

Figure 1 shows the evolution of microstructure in the laminate after five ARB cycles during annealing in the temperature range $\mathrm{RT}-480^{\circ} \mathrm{C}$. Broken AlMg3 layers and touching $\mathrm{Al}$ ones are observed in the as processed material with signs of partial (post)dynamic recrystallization in Al layers. Significant static recrystallization starts in Al layers above $200^{\circ} \mathrm{C}$ and at $320^{\circ} \mathrm{C}$ fully recrystallized equiaxed grains are formed. At higher annealing temperatures their coarsening constrained by the layer thickness (around 70-80 $\mu \mathrm{m}$ ) occurs. Only limited signs of recrystallization were found in AlMg3 layers below $320^{\circ} \mathrm{C}$. However, at this annealing temperature and at higher ones fast recrystallization proceeds followed by a partial grain coarsening. At the final annealing temperature the average grain size in AlMg3 layer reaches almost $50 \mu \mathrm{m}$.

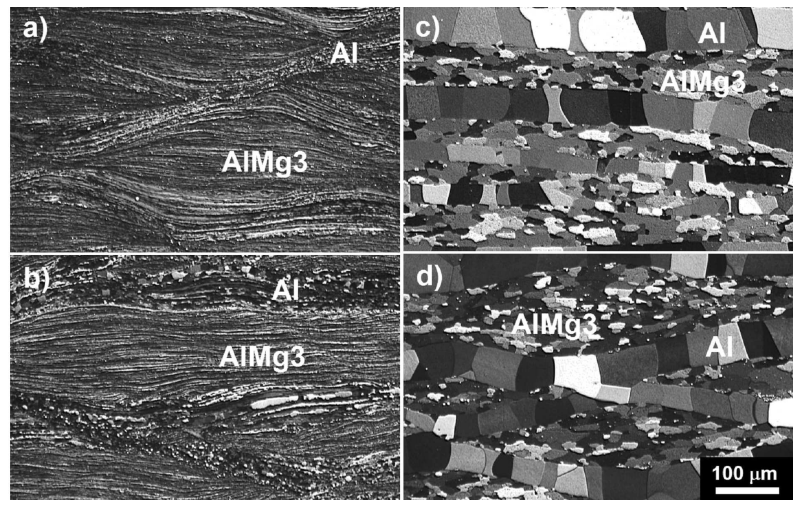

Fig. 1. Evolution of microstructure in Al99.99/AlMg3 laminate in the initial state after five ARB cycles (a) and annealing up to $200{ }^{\circ} \mathrm{C}(\mathrm{b}), 320^{\circ} \mathrm{C}$ (c), and $480{ }^{\circ} \mathrm{C}$ (d).
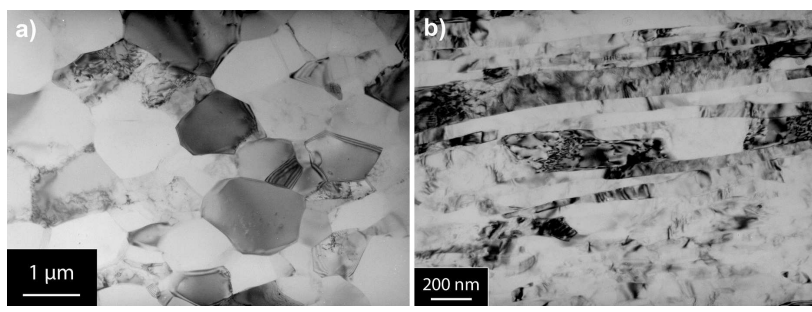

Fig. 2. TEM micrographs of the initial microstructure in Al layer (a) and AlMg3 layer (b).

TEM observations performed on annealed specimens correspond with LOM data (Fig. 2). Al layers in the initial state after ARB contain a mixture of well-developed subgrains and also small recrystallized grains (grain size around two $\mu \mathrm{m}$ ) with clearly defined high-angle grain boundaries. AlMg3 layers consist of lamellar subgrains with numerous dislocations arranged in dense dislocation tangles and cell-walls.

At $200^{\circ} \mathrm{C}$ no changes were observed in $\mathrm{Al}$ layers while partial recovery of the dislocation substructure without

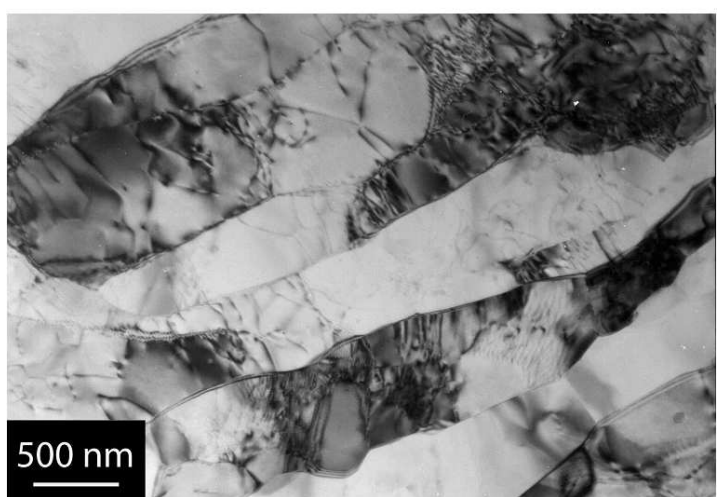

Fig. 3. Subgrains in AlMg3 layer after annealing at $200{ }^{\circ} \mathrm{C}$.
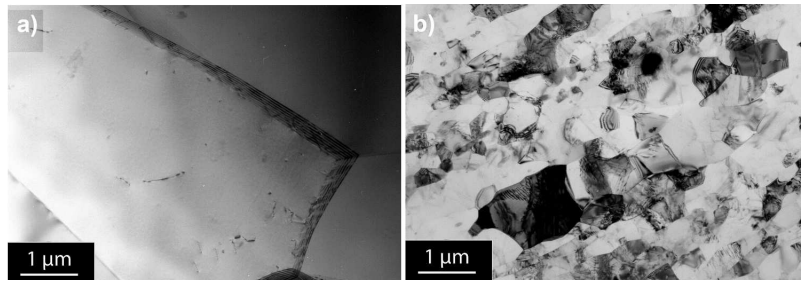

Fig. 4. Fully recrystallized grains in $\mathrm{Al}$ layer (a) and subgrains in AlMg3 layer (b) after annealing at $280^{\circ} \mathrm{C}$.

any subgrain growth appear in the AlMg3 layers as can be seen in a detailed Fig. 3. The Al layers are fully recrystallized at $280^{\circ} \mathrm{C}$. AlMg3 ones exhibit only a coalescence of subgrains (Fig. 4). Above this temperature recrystallization occurs also in AlMg3 layers accompanied by a precipitation of fine dispersion of $\mathrm{Mn}$ rich $\mathrm{Al}_{6} \mathrm{Mn}$ particles.

A boundary area of the original $\mathrm{Al} / \mathrm{AlMg} 3$ interface after annealing at $480^{\circ} \mathrm{C}$ is displayed in Fig. 5. The image clearly shows a growth of a grain from the Al layer into the AlMg3 layer. This phenomenon was confirmed also by in situ annealing observations. An annealing scheme $50^{\circ} \mathrm{C} / 50$ min was used during in situ measurements in order to keep the same effective heating rate as the one used in static experiments.

The evolution of microstructure at the interface is shown in Fig. 6. In the initial state the interface is well defined because very thin subgrains of the AlMg3 layer are easily recognizable. However, with increasing annealing temperature recrystallization occurs in both materials and finally at $450{ }^{\circ} \mathrm{C}$ a grain boundary of a grain from the Al layer penetrates the original interface. Similar penetration of grain boundaries into a neighboring layer was observed also by Quadir et al. [5] in laminates composed from high purity aluminum and Al-Sc alloy. This effect was attributed to the mobility of grain boundaries in Al layers. Nevertheless, authors expected that this broadening of layers occurs in the early stages of annealing when no strengthening particles are present in the 


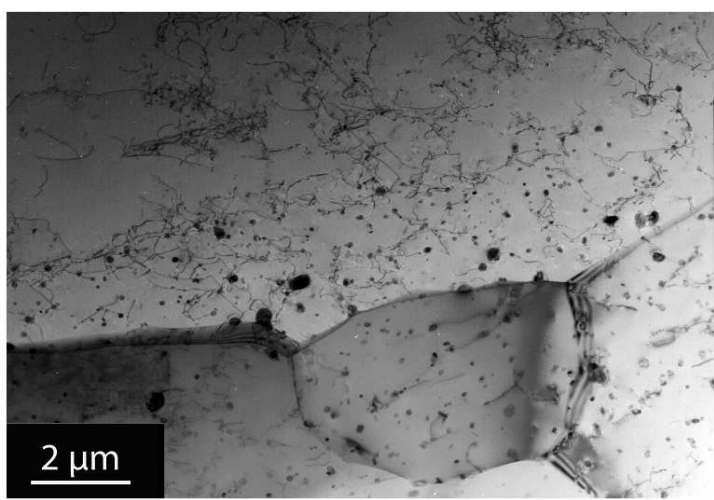

Fig. 5. Interface between original $\mathrm{Al}$ and $\mathrm{AlMg} 3$ layers after annealing at $480{ }^{\circ} \mathrm{C}$. The original AlMg3 layer (bottom of the image) contains Mn-rich particles. Residual dislocations appear as an artifact of quenching from high temperature.

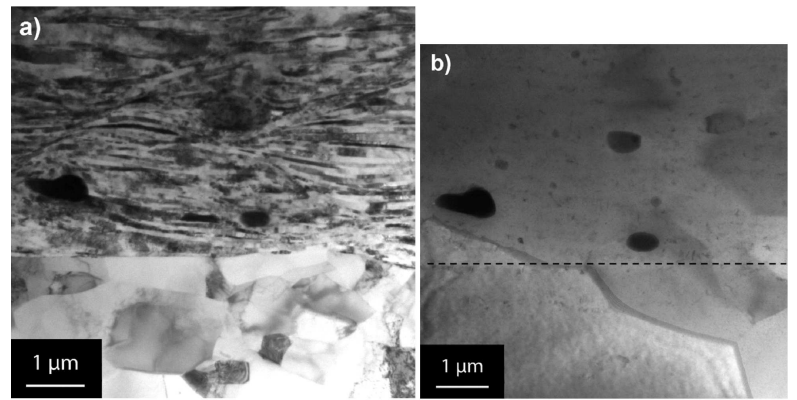

Fig. 6. Microstructure of an interface between $\mathrm{Al}$ and AlMg3 layers after 5 ARB cycles (a) and in situ annealing at $450^{\circ} \mathrm{C}(\mathrm{b})$. The position of the original interface is schematically indicated by a dashed line.

Al-Sc alloy. On the contrary, no such effect was observed by Chekhonin et al. [6] in aluminum laminates consisting of high purity aluminum and commercially pure aluminum. Therefore the presence of this effect depends on the purity of materials, presence of particles and solute atoms, and on the quality of the surface treatment before each ARB cycle. Results of Chekhonin et al. [6] indicate non-marginal role of the driving pressure for grain coarsening at the interface, which increases with the increase of a gap in the deformation substructure and grain size. The presence of impurities or solutes, on the other hand, significantly decreases the mobility of grain boundaries [7].

In our composite a very different chemical composition was used in both layers. Nevertheless, due to a diffusion enhanced by increasing annealing temperatures changes in the solute elements distribution occur. A monitoring of solute redistribution was done by electrical resistivity measurements.

Experimental data in Fig. 7 exhibit a local decrease of resistivity below $300^{\circ} \mathrm{C}$. Such a behavior is typical for heavily deformed aluminum alloys and is always connected with the recovery of the dislocation substructure [8] and precipitation of $\mathrm{Mn}$ rich particles $[9,10]$.
The following significant increase of resistivity could not be explained by a simple dissolution of particles because TEM observations shows an opposite effect - formation of Mn-rich particles, which is always connected with the decrease of resistivity $[9,10]$. Nevertheless, the diffusion of solutes $(\mathrm{Mg}, \mathrm{Mn}, \mathrm{Fe})$ into $\mathrm{Al}$ layers is highly probable. Especially, the high magnesium content in AlMg3 layers and sufficiently high diffusion coefficient $\left(15 \times 10^{-20} \mathrm{~m}^{2} / \mathrm{s}\right.$ at $450 \mathrm{~K}$ ), which is by seven orders higher than for iron or manganese [11], must be accounted. A simplified model based on the Fick law [12] for diffusion of $\mathrm{Mg}$ from AlMg3 layers into Al layers was used to evaluate this effect. The model takes into account a constant width of layers, effect of magnesium atoms on resistivity of aluminum [13] and specific heating regime during annealing.

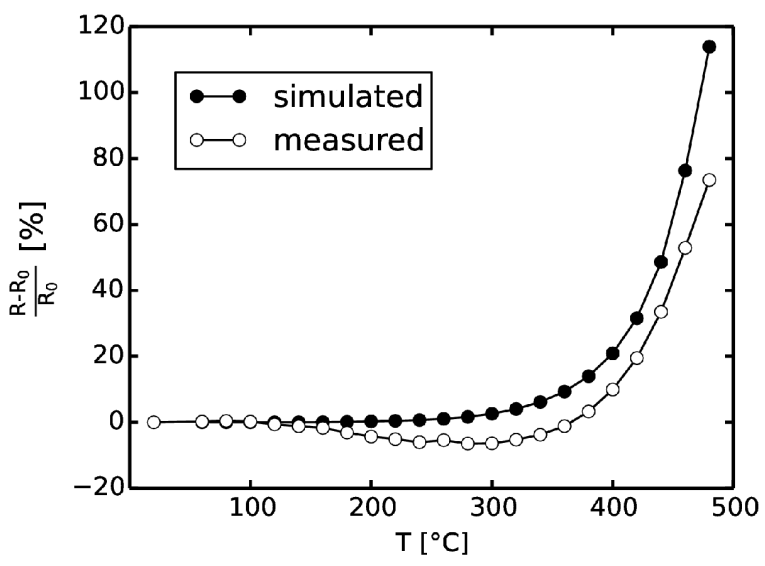

Fig. 7. Experimental and simulated changes of relative resistance $R$ during isochronal annealing. $R$ is the value of resistance in the initial state after ARB processing.

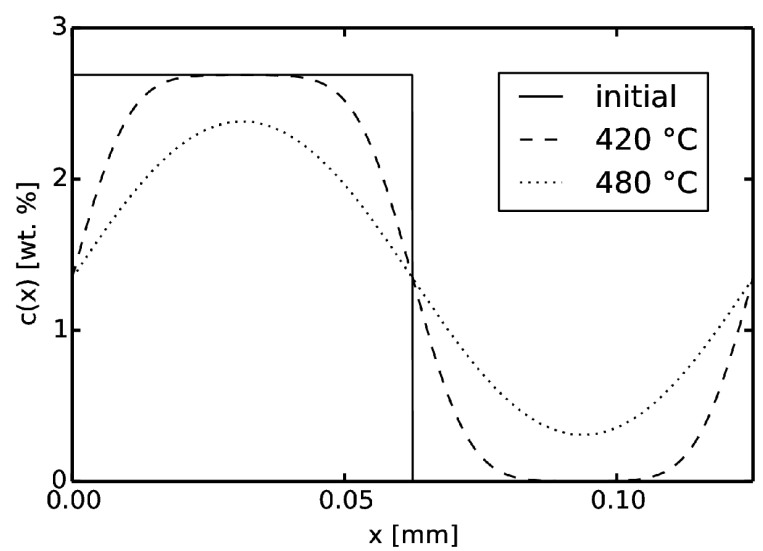

Fig. 8. Simulated profile of magnesium concentration $c$ in two neighboring layers in the initial state and after annealing at 420 and $480^{\circ} \mathrm{C}$.

Concentrations of $\mathrm{Mg}$ in two neighboring layers in the initial state and at two selected temperatures are given in Fig. 8. Calculated values of relative resistance changes during the whole annealing process are shown in Fig. 7. Despite the roughness of the model the simulated data give a good correspondence with the measured ones. 
At this point it is important to note that no influence of recovery of the dislocation substructure or recrystallization, as well as the role of Mn-rich particles formation, were considered in our simulations. Nevertheless, simulations clearly show that changes in $\mathrm{Mg}$ distribution can increase the mobility of grain boundaries near the interface on the AlMg3 side at higher annealing temperatures and thus enhance the probability of broadening of the Al layer.

\section{Summary}

Evolution of microstructure in A199.99/AlMg3 laminates prepared by ARB was studied in the course of isochronal annealing. The main results lead to the following conclusions:

1. A composite consisting of 32 alternating layers of A199.99 and AlMg3 alloy were ARB processed.

2. Partial recrystallization occurs in the pure Al layer while flat and elongated subgrains are formed in AlMg3 ones.

3. Fast recrystallization and grain growth were observed in pure Al layers in the course of annealing. This process is considerably retarded in AlMg3 layers due to the presence of solutes and particles.

4. Extensive diffusion of $\mathrm{Mg}$ atoms into pure Al layers is responsible for the increase of electrical resistance of the material. This diffusion, on the other hand, enhances the probability of penetration of grain boundaries through the original interface between two neighboring layers.

\section{Acknowledgments}

Financial support of Czech Science Foundation is gratefully acknowledged (project No. P107-12-0921).

\section{References}

[1] Y. Saito, H. Utsunomiya, N. Tsuji, T. Sakai, Acta Mater. 47, 579 (1999).

[2] M. Slámová, P. Homola, P. Sláma, M. Karlík, M. Cieslar, Y. Ohara, N. Tsuji, Mater. Sci. Forum 519521, 1227 (2006).

[3] E. Ma, JOM 56, 49 (2006).

[4] M. Slámová, P. Sláma, P. Homola, J. Uhlír̆, M. Cieslar, Int. J. Mater. Res. 100, 858 (2009).

[5] M.Z. Quadir, O. Al-Buhamad, L. Bassman, M. Ferry, Acta Mater. 55, 5438 (2007).

[6] P. Chekhonin, B. Beausir, J. Scharnweber, C.-G. Oertel, T. Hausol, H.W. Hoppel, H.-G. Brokmeier, W. Skrotzki, Acta Mater. 60, 4661 (2012).

[7] H. Yamagata, Acta Met. Mater. 43, 723 (1995).

[8] M. Poková, M. Zimina, M. Cieslar, Int. J. Mater. Res. 106, 676 (2015).

[9] M. Slámová, P. Sláma, M. Cieslar, Mater. Sci. Forum 519-521, 365 (2006).

[10] M. Poková, M. Cieslar, J. Lacaze, Acta Phys. Pol. A 122, 625 (2012).

[11] P.E.J. Rivera Diaz del Castillo, P. Reischig, S. van der Zwaag, Scr. Mater. 52, 705 (2005).

[12] Thermodynamics and Kinetics in Materials Science: A Short Course, Eds. B.S. Bokshtein, M.I. Mendelev, D.J. Srolovitz, Oxford University Press, Oxford 2005.

[13] Aluminum: Properties and Physical Metallurgy, Ed. J.E. Hatch, ASM, 1984. 